\title{
Analyzing dynamic disturbance fragmentation mechanism of surrounding rock in roadway roof
}

\author{
Hongfei Gu${ }^{1}$, Qingfeng $\mathrm{Li}^{2}$, Yuejin Peng ${ }^{3}$, Qiyun Huang ${ }^{4}$, Jianan Yang \\ $1,3,4,5$ School of Resource and Environment and Safety Engineering, Hunan University of Science and \\ Technology, Xiangtan, Hunan, 411201, China \\ ${ }^{2}$ Institute of Mineral Engineering, Hunan University of Science and Technology, \\ Xiangtan, Hunan, 411201, China \\ ${ }^{2}$ Corresponding author \\ E-mail: ${ }^{1} h f g u @ m a i l . h n u s t . e d u . c n,{ }^{2} l q f 66 @ h n u s t . e d u . c n,{ }^{3}$ pengyuejin430@163.com, \\ 4qiyunhuang@hotmail.com, ${ }^{5}$ Yjn0628@163.com
}

Received 2 January 2019; received in revised form 30 April 2019; accepted 14 May 2019 DOI https://doi.org/10.21595/jve.2019.20497

Check for updates

Copyright (C) 2019 Hongfei Gu, et al. This is an open access article distributed under the Creative Commons Attribution License, which permits unrestricted use, distribution, and reproduction in any medium, provided the original work is properly cited.

\begin{abstract}
In this paper, a numerical simulation is conducted to analyze an engineering practice pertaining to the in panel 2347, the discussion is focused on the following aspects: the influence of fault mining activation on fragmentation of surrounding rock in roof, surrounding rock failure of unsupported roadway under static load alone, surrounding rock failure of unsupported roadway under dynamic load and static load combination, damage of surrounding rock in supporting roadway under dynamic load and static load combination. The results show that, for the roadway surrounding rock with obvious dynamic disturbance, the compressive stress value can eliminate the influence of the tensile stress wave generated by the reflection of the compressive stress disturbance wave on the roadway wall. In the roadway support, it should provide a certain compressive stress to the surrounding rock of the surrounding roadway wall. An anchor support surrounding rock can significantly inhibit the tensile crack, shear the crack expansion and dislocation slip of coal gang, and it can also alleviate the tensile, compressive and shear failure of the roof carbonaceous mudstone. Because the dynamic load has a significant damage to the carbonaceous mudstone between roof anchors, it is necessary to reduce the anchor spacing and row spacing or enhance the stiffness and active stress of the protective surface member.
\end{abstract}

Keywords: roadway surrounding rock, dynamic disturbance, anchor support, numerical simulation.

\section{Introduction}

At present, it is popular to employ the comprehensive mining hydraulic powered support in the mineral resources mining industry. Although this method significantly reduces the occurrence of safety accidents in the industry, the dynamic disturbance phenomenon still appears in the roadway, which drives many experts to investigate the stability of surrounding rock of roadway after dynamic disturbance.

Literatures [1,2] studied the propagation and attenuation characteristics of dynamic disturbance waves in coal-rock media, it provides a theoretical basis for studying the stability of roadway surrounding rock;

In literatures [3-7], discussions were given on the damage behavior of surrounding rock of roadway under dynamic disturbance from the perspective of numerical simulation and experiment, the results demonstrated that the surrounding rock fracture process does not depend on the direction of local dynamic disturbance; besides, when the dynamic disturbance appears, the surrounding rock of the roadway is mainly broken along the section. In literatures [8-10], the mechanical behavior of the defective rock under stress is studied by experiments and numerical simulations. In literatures [11-13], investigations were conducted for the thermal imaging and spectral properties of the failure process of inclined surrounding rock roadway, it is found that the mechanical properties of rocks are greatly affected by dynamic disturbances. In literatures [14-16], 
the mechanics and seepage characteristics of rock under confining pressure are studied experimentally. In literatures $[17,18]$, a U-shaped steel support scheme was proposed to handle the issue of the roadway surrounding rock support, which was based on the displacement, plastic zone and principal stress difference distribution under different support schemes.

Literatures [19-23] obtained a stress environment to regulate the energy accumulation of the bottom plate. This technique can reduce the impact of strong pressure on the floor of the roadway, and eliminate the danger of rock burst, whereby a new "anchor-rope-net-spray concrete shell" combined support scheme is proposed for the ventilating roadway. In literatures [24-26], the stress and strain behavior of the fault-bearing rock was studied through a series of creep tests. Based on the dynamic model, Literature [27] proposed a dynamic instability criterion of the layer plate structure. In summary, the above studies focused on the influence of dynamic disturbance on the stability of surrounding rock of roadway and surrounding rock support of roadway, and few studies considered the mechanism of dynamic disturbance and fragmentation of surrounding rock in mining roadway and its control measures.

In this paper, a numerical simulation is conducted to analyze an engineering case pertaining to the in panel 2347, the discussion is focused on the following aspects: the influence of fault mining activation on fragmentation of surrounding rock in roof, surrounding rock failure of unsupported roadway under static load alone, surrounding rock failure of unsupported roadway under dynamic load and static load combination, damage of surrounding rock in supporting roadway under dynamic load and static load combination. Compared to existing works, the contribution of this paper is three-fold:

1. It obtains the mechanism of controlling the dynamic disturbance method of surrounding rock in roadway.

2. It obtains the mechanism of anchor controlling the dynamic disturbance of surrounding rock in roadway.

3. It obtains the mechanism of improving the anchor control dynamic disturbance effect of surrounding rock in roadway.

\section{Engineering situation}

\subsection{Working face mining situation}

At panel 2347, the coal seam thickness $1.8 \mathrm{~m}-2.7 \mathrm{~m}$. As shown in Fig. 1, affected by faults and syncline, section 13\# of panel 2347 is seriously deformed after mining, the working face advance direction is perpendicular to the F3 fault, the distance between the final stop line and the vertical line of the 13\# section roadway is $22.7 \mathrm{~m}$. The F3 fault is a reverse fault with a drop of $5 \mathrm{~m}-10 \mathrm{~m}$, fault dip $48^{\circ}$, there is a syncline at $27.5 \mathrm{~m}-50 \mathrm{~m}$ from the $\mathrm{F} 3$ fault, panel 2347 internal tectonic stress complex.

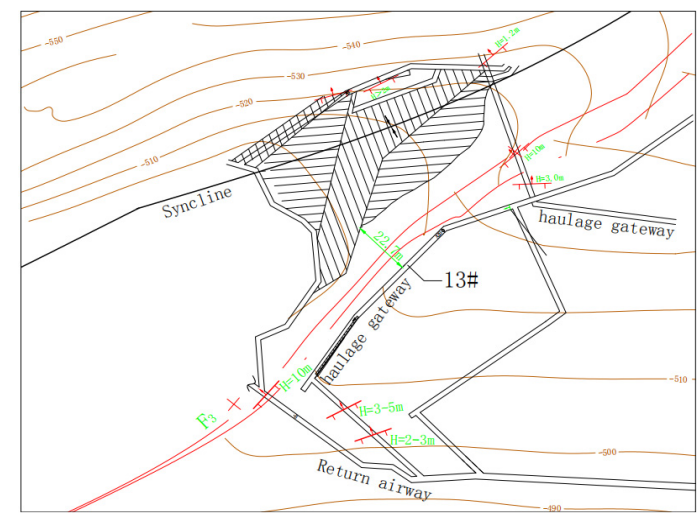

Fig. 1. Mining diagram of panel 2347 
With the 2347 work facing forward, the vertical distance between the working face and the F3 fault and the haulage roadway is gradually reduced, the impact of mining on fault activation and roadway surrounding rock deformation is also intensifying, and it is necessary to further analyze the mining impact.

\begin{tabular}{|c|c|c|c|}
\hline Histogram & Name & Thickness/m & Lithology \\
\hline Fine sandstone & 1.8 & $\begin{array}{c}\text { Light color medium fine clastic, } \\
\text { 0ffwhite, Medium thickness, Layered }\end{array}$ \\
\hline Sandy mudstone & 6.20 & Light gray, Thin to medium thick, Layered \\
\hline & Carbon mudstone & $0.8-1.4$ & Black, Scaly \\
\hline & Santhly coal seam & $1.7-2.7$ & Simple structure, Excellent quality \\
\hline & Medium sandstone & 3.0 & Light gray, Medium thickness, Layered \\
\hline
\end{tabular}

a)

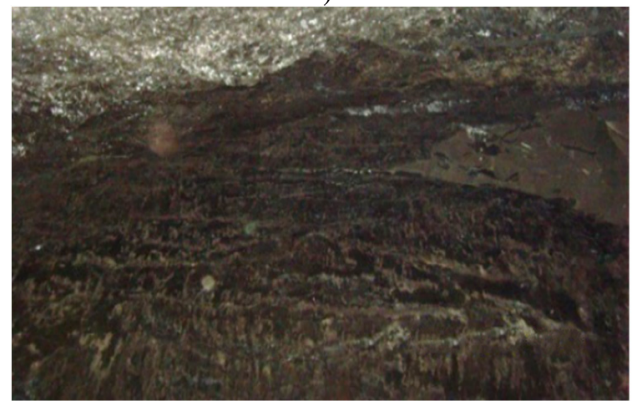

b)

Fig. 2. a) 2347 working face coal seam comprehensive histogram,

b) carbonaceous mudstone of the roof surrounding rock

\subsection{The situation of rock covered above the coal seam}

As shown in Fig. 2(a), the direct top of the fourth coal seam is carbonaceous mudstone, thickness, sandy mudstone, their thickness is $0.8 \mathrm{~m}-1.4 \mathrm{~m}, 6.2 \mathrm{~m}$, the main roof is $1.8 \mathrm{~m}$ thick fine sandstone, as shown in Fig. 2(b). The first, second and third coal seams overlying the four coals have been fully mined, the total coal seam thickness of the first, second and third coal seams is $4.5 \mathrm{~m}$, it can be known from the calculation of Buildings, water, railways and main well lane leaving coal pillar with compressed coal mining specification, it's water-conducting fracture zone height is $52 \mathrm{~m}$. In addition, it can be known from the coal seam comprehensive histogram, there are three layers of hard, medium-thick to thick layered rock formations in the overlying strata of coal-bearing strata, dark gray, they are light gray to white feldspar quartz fine sandstone (average thickness $8.79 \mathrm{~m}$ ) in pseudo-integrated contact with coal-bearing strata medium-thick to thick layered; medium-thick to thick-layered, light-gray to gray-white medium feldspar quartz sandstone with an average distance of $165 \mathrm{~m}$ from coal-bearing strata (average thickness $255 \mathrm{~m}$ ); medium-thick to thick-layered, light-gray to gray-green sandy mudstone with an average distance of $549 \mathrm{~m}$ from coal-bearing strata (average thickness $41 \mathrm{~m}$ ). Combined with the analysis of key strata theory, there is a main key layer under the conditions of the first, second, third and fourth coal seams, the main key layer is medium-thick to thick layered, light gray to grayish white feldspar quartz sandstone with an average distance of $165 \mathrm{~m}$ from coal-bearing strata, but its dune cross-bedding is more developed, a thin layer of sandy mudstone is often sandwiched in the middle, and under the influence of large drop faults, the integrity of the main key stratum is affected, the control of overlying strata will be weakened, increased mining pressure on mining coal seams, the 
surrounding rock vertical stress of the transportation roadway is significantly higher than other roadways in the mining area, so that the transportation roadway is in a high stress environment, In addition, since the mining is easy to activate the fault, the dynamic disturbance caused by the fault activation, and exacerbates the damage of the 13\# section of the high-stress transport lane.

\subsection{Deformation properties of carbonaceous mudstone}

Carbonaceous mudstone refers to mudstone containing carbonaceous components, generally, the organic carbon content is $10 \%-30 \%$. "mudstone" is also called clay rock, mainly composed of fine particles with a particle size of less than $0.0039 \mathrm{~mm}$, its main component is clay mineral, followed by quartz, muscovite and a small amount of feldspar, the texture is brittle and easy to break. In addition, carbonaceous mudstone has many fine pores and cracks, mostly in the form of flakes, smooth between layers, no bond force, easy weathering, hydrophilic, soften and disintegrate under loose or weathered conditions and loosely break, surrounding rock strength drops rapidly after disturbance.

\subsection{Roadway support and fragmentation of surrounding rock in roof}

The roadway has a depth of $691 \mathrm{~m}$ and a vertical stress of $17 \mathrm{MPa}$, the roadway section adopts trapezoid, the designed net width is $2.4 \mathrm{~m}$ and a net height of $2.1 \mathrm{~m}$. It is supported by I-beam steel shed and the shed distance is $0.7 \mathrm{~m}$, top laying bamboo stalks and other materials. The advanced support of the working face adopts a single hydraulic prop with a $\pi$ beam, there is a beam and three pillars under the beam, $\pi$ beam length $2.4 \mathrm{~m}$.

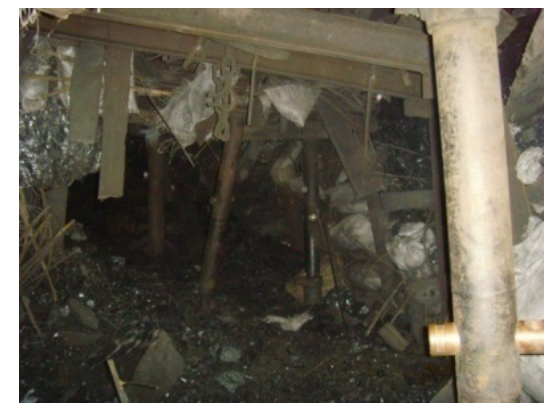

Fig. 3. The floor heave of roadway is serious

As can be seen from Fig. 3, the extrusion and bottom drum effects on the underside of the roadway (on the side of the goaf) are clearly visible; the carbon mudstone and top coal below immediate roof are seriously damaged and broken into granular, but the immediate roof is basically complete. The literatures [28, 29] shows that for the surrounding rock where the horizontal stress is the maximum principal stress, as the side pressure coefficient continues to increase, the main stress concentration degree gradually shifts from both sides of the roadway to the top and bottom plates; When the stress exceeds the strength of the surrounding rock, the process of destroying instability is: floor without support, floor heave, roadway's sides sinking and convergence deformation, abscission layer and sinking of the roof, whole section shrinkage deformation. Obviously, the deformation and failure modes of the surrounding rock of this roadway are quite different from those under non-mining conditions, it is necessary to further analyze from the aspects of surrounding rock structure and mining conditions.

\section{Model introduction}

In engineering situation, positional relationship between mining roadway and fault and adjacent working face, as shown in Fig. 4, the F3 fault could change the periodic breaking interval 
of the main top, moreover, it may cause bending and shear failure of the main top fault zone rock, and then the main roof along the fault zone slip, the underlying roadway under the fault will undergo large deformation due to the influence of dynamic and static loads.

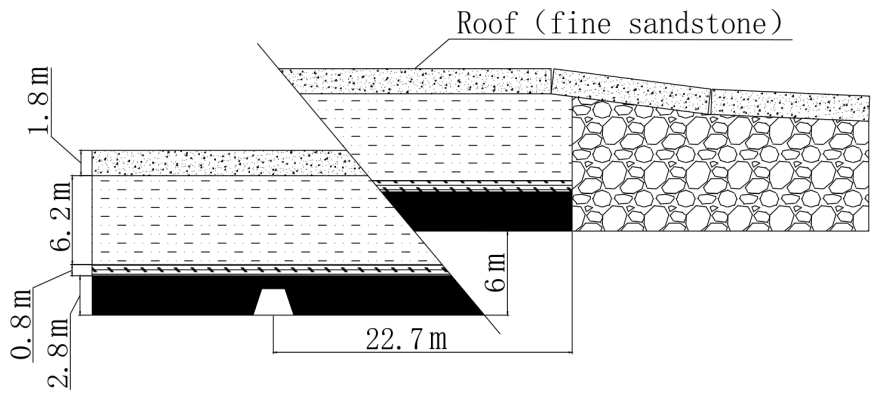

Fig. 4. Positional relationship between mining roadway and fault and adjacent working face

RFPA (Rock Failure Process Analysis) is a numerical calculation method for material fracture process analysis based on finite element stress analysis and statistical damage theory, it is a numerical test tool that simulates the process from progressive cracking to instability. According to Fig. 4, Fig. 1, Fig. 2(a), the RFPA calculation model under the non-support condition is shown in Fig. 5. To analyze the influence of the active support form of the anchor on the stability of the surrounding rock in the roadway, the RFPA calculation model for the surrounding rock in the roadway with support is shown in Fig. 10, because only the influence of bolt support on the roof carbonaceous mudstone is considered, no anchor cable is added to the model, and the rock size is $50 \mathrm{~m} \times 100 \mathrm{~m}$ and the ratio is $1: 1$. The mohr-coulomb model is used in this paper. The specific rock mechanics parameters are shown in Table 1.

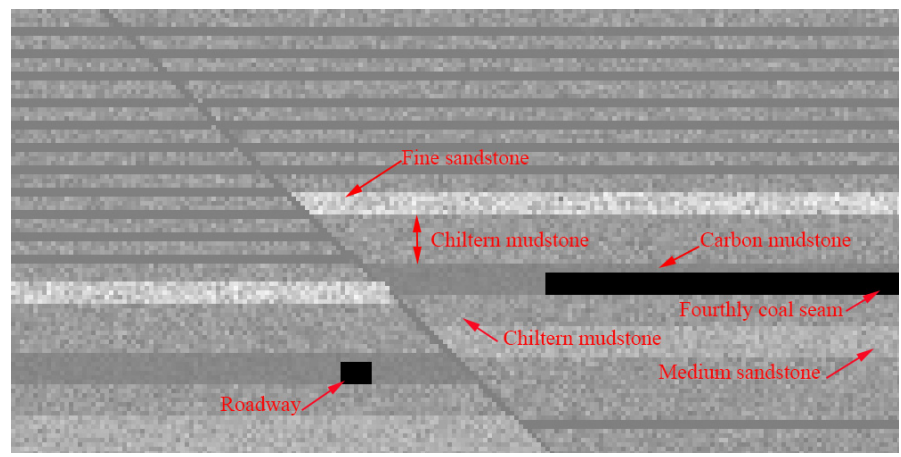

Fig. 5. Numerical model diagram

Table 1. Mechanical parameters of coal seam and strata

\begin{tabular}{|c|c|c|c|c|c|c|c|}
\hline $\begin{array}{c}\text { Coal seam and } \\
\text { strata }\end{array}$ & $\begin{array}{c}\text { Homoge- } \\
\text { neous } \\
\text { degree }\end{array}$ & $\begin{array}{c}\text { Elastic } \\
\text { modulus / } \\
\text { GPa }\end{array}$ & $\begin{array}{c}\text { Compressive } \\
\text { strength } \\
\text { / MPa }\end{array}$ & $\begin{array}{c}\text { Compression- } \\
\text { tension } \\
\text { ratio }\end{array}$ & $\begin{array}{c}\text { Density / } \\
\text { g.cm }\end{array}$ & $\begin{array}{c}\text { Poisson } \\
\text { ratio }\end{array}$ & $\begin{array}{c}\text { Internal } \\
\text { friction } \\
\text { angle / }\end{array}$ \\
\hline Fine sandstone & 5 & 80 & 100 & 10 & 2.5 & 0.25 & 25 \\
\hline Sandy mudstone & 3 & 30 & 40 & 10 & 2.5 & 0.3 & 30 \\
\hline $\begin{array}{c}\text { Carbon } \\
\text { mudstone }\end{array}$ & 3 & 10 & 15 & 10 & 2.5 & 0.35 & 35 \\
\hline $\begin{array}{c}\text { Fourthly coal } \\
\text { seam }\end{array}$ & 3 & 10 & 15 & 10 & 1.4 & 0.35 & 35 \\
\hline $\begin{array}{c}\text { Medium } \\
\text { sandstone }\end{array}$ & 3 & 50 & 60 & 10 & 2.5 & 0.25 & 25 \\
\hline Joint & 50 & 1 & 10 & 50 & 2.0 & 0.3 & 30 \\
\hline
\end{tabular}




\section{Numerical results and analysis}

\subsection{Fault mining-induced activation and its mining-induced stress generated in surrounding rock of roadway}

As shown in Fig. 6, as the coal seam advances in the direction of the roadway, the roof rock above the coal seam is gradually tensile and compress failure from the bottom to the top. According to the rock pressure observation data of panel 2347, periodic weighting interval $10 \mathrm{~m}-15 \mathrm{~m}$, the main roof cantilever break distance in the above simulation is $15 \mathrm{~m}(5 \mathrm{~m}$ excavation in the simulation), that is, the periodic weighting interval in the simulation is consistent with the actual periodic weighting interval, and the surrounding rock pressure of the actual roadway is similar to the simulation data, and experience the dynamic disturbance of the main roof sliding mode fracture and fault activation slip, as shown in Fig. 7 and Fig. 8. In summary, when performing the dynamic damage analysis of the dynamic disturbance to carbonaceous mudstone, the vertical and horizontal stresses in the static pressure of surrounding rock are 4.7 $\mathrm{MPa}$ and 5 MPa respectively, the dynamic disturbance pressure in the vertical direction of the roof is $0.5 \mathrm{MPa}$.

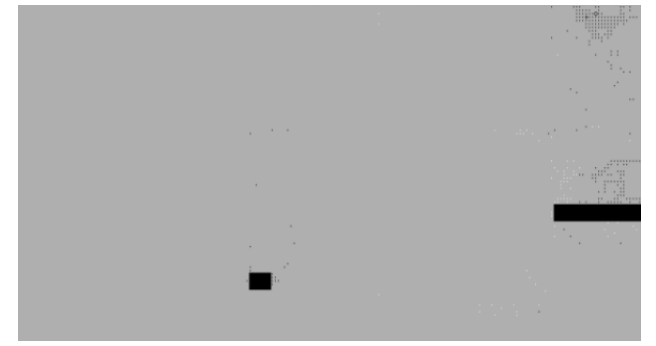

a)

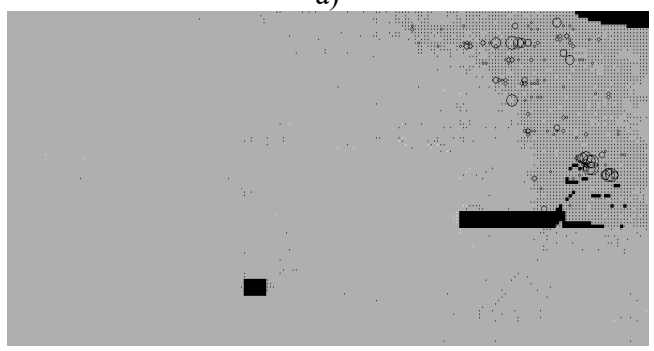

c)

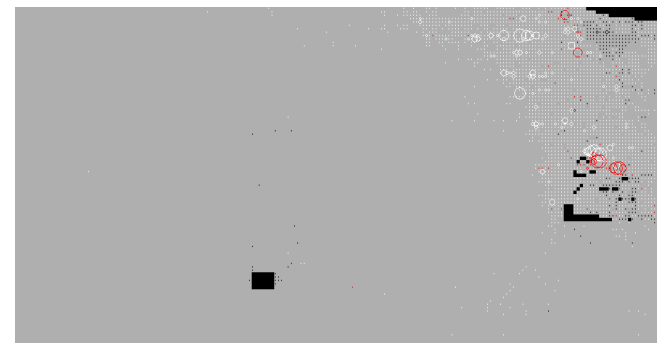

b)

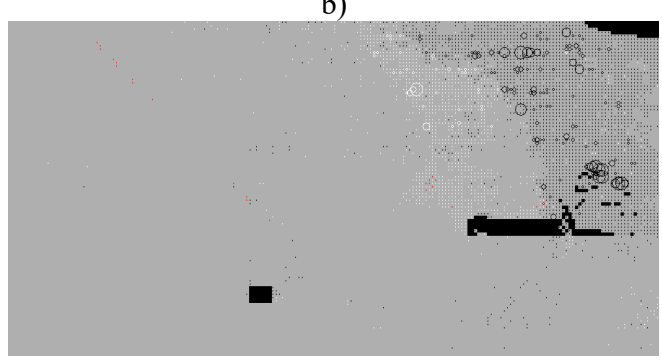

d)

Fig. 6. Rock formation fracture and slip instability and its acoustic emission during mining

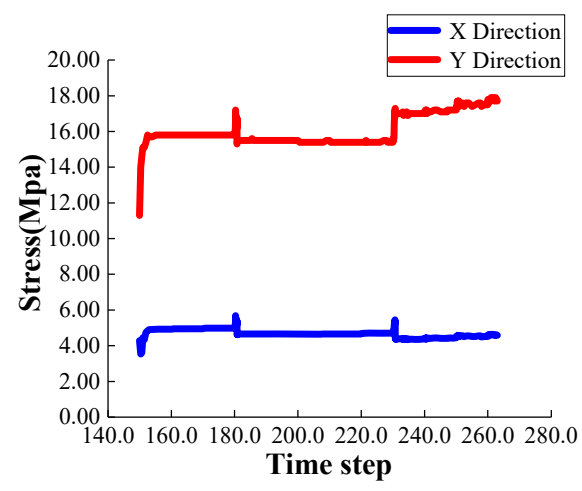

a)

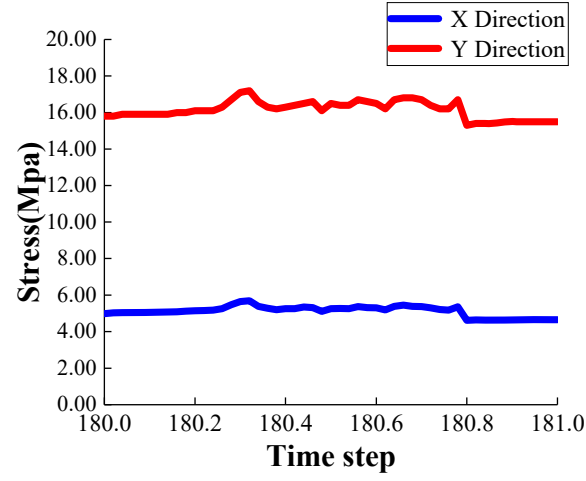

b)

Fig. 7. Mining stress near the sides of the fault 
ANALYZING DYNAMIC DISTURBANCE FRAGMENTATION MECHANISM OF SURROUNDING ROCK IN ROADWAY ROOF. Hongfei Gu, QINGFeng Li, YueJIN PENG, QIYUn HuAng, JiANAN YANG

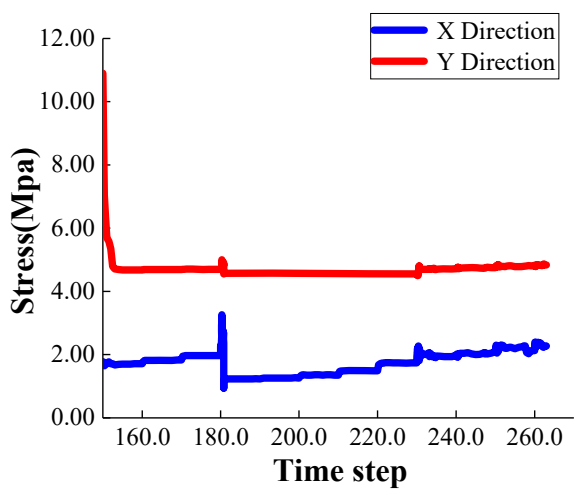

a)

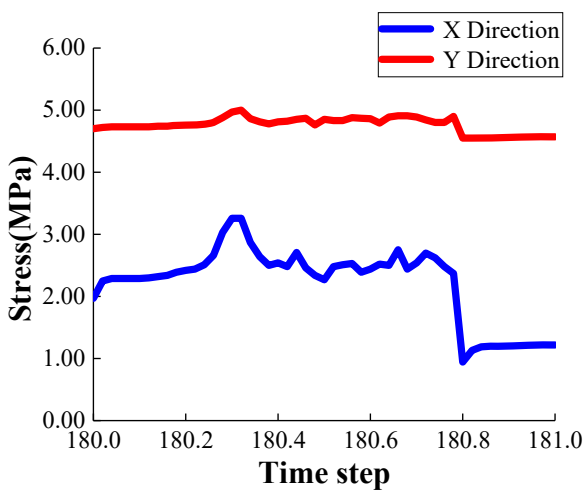

b)

Fig. 8. Roadway roof mining-induced stress

\subsection{Dynamic failure of carbon mudstone by fault activation slip}

To analyze the damage of roof carbonaceous mudstone under dynamic disturbance, the surrounding rock around the roadway is the research object, trapezoidal time step load is $[(0,0),(100 \mu \mathrm{s}, 0.5 \mathrm{MPa}),(200 \mu \mathrm{s}, 0.5 \mathrm{MPa}),(300 \mu \mathrm{s}, 0 \mathrm{MPa})]$, use the above loads to simulate the effects of dynamic disturbances, applied vertically to sandy mudstone. Under the condition of no support, the surrounding rock damage under the combined load of static load and static and dynamic as shown in Fig. 9, among them, red means tensile failure, white means shear failure. It can be seen from comparison between Fig. 9(b) and Fig. 9(a), after applying the normal dynamic load on the roof sandy mudstone, the carbon mudstone is seriously damaged in the surrounding rocks of near roadway wall and central part of the roof, and gradually weakens into the deep part of the surrounding rock, it shows that the compressive stress wave generates a tensile stress reflected wave on the free surface, the effect of the tensile stress reflected wave on the free surface is obvious. For roadway surrounding rock with obvious dynamic disturbance, the compressive stress wave generates a tensile stress reflected wave on the roadway wall, the compressive stress value can eliminate the above-mentioned tensile stress wave influence, in the roadway support, it is necessary to provide a certain compressive stress to the surrounding rock of the surrounding roadway wall.

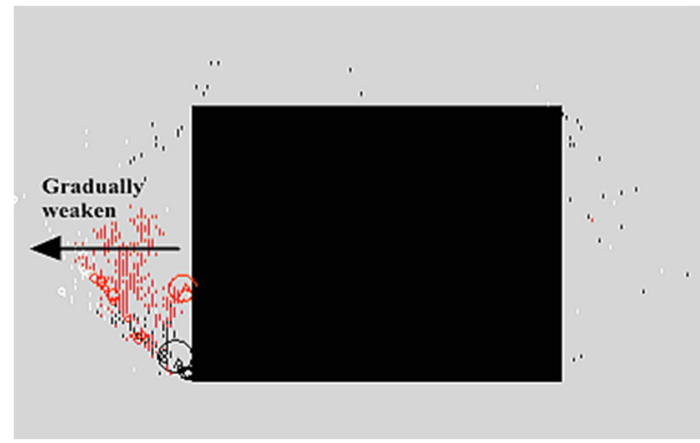

a)

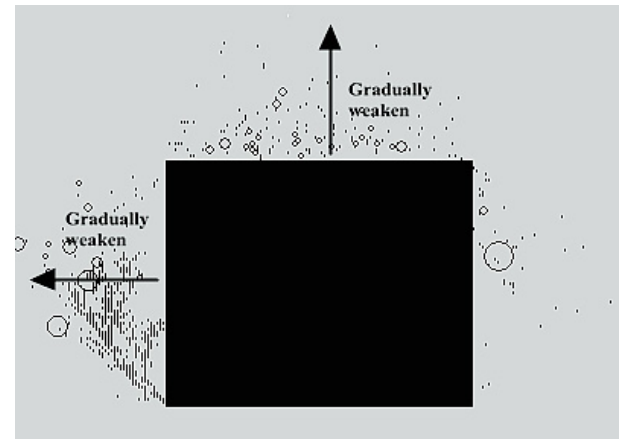

b)

Fig. 9. Surrounding rock failure in unsupported roadway under different stress environments:

a) under static load, b) under the combined action of dynamic load and static load

To analyze the influence of anchor support on the stability of surrounding rock (anchor support is the active support method), create a calculation model of the supported roadway as shown in Fig. 10, since only the effect of anchor support on the roof carbonaceous mudstone is considered, no anchor cable is added in the model. The supported roadway surrounding rock failure under the 
combined action of dynamic load and static load is shown in Fig. 11. Comparing Fig. 11 with Fig. 9(b), after anchoring the surrounding rock, significantly inhibited the expansion and dislocation slip of tensile cracks and shear cracks on both sides of the roadway, it has a good inhibitory effect on the tensile and compressive failure of carbonaceous mudstone in the roof and it also has a good inhibitory effect on the shear failure of the top carbonaceous mudstone. Because the dynamic load damage to the carbonaceous mudstone between the roof anchors is obvious, the anchor spacing and row spacing should be reduced or enhance the stiffness and main power of the protective surface member.

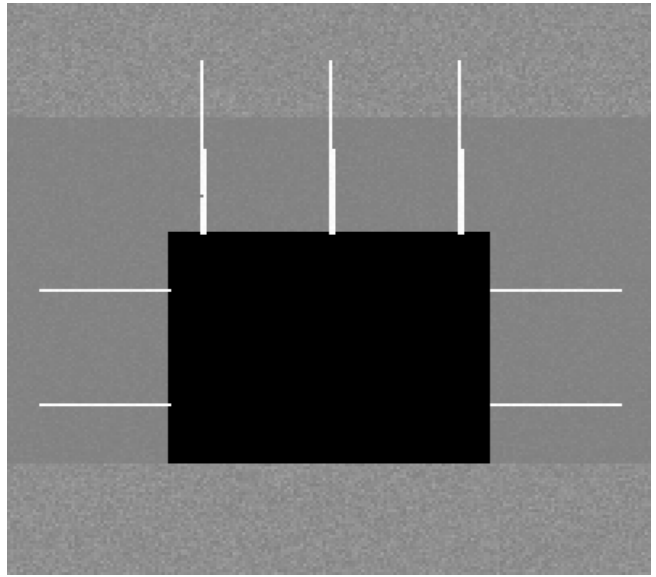

Fig. 10. Numerical simulation of anchor support

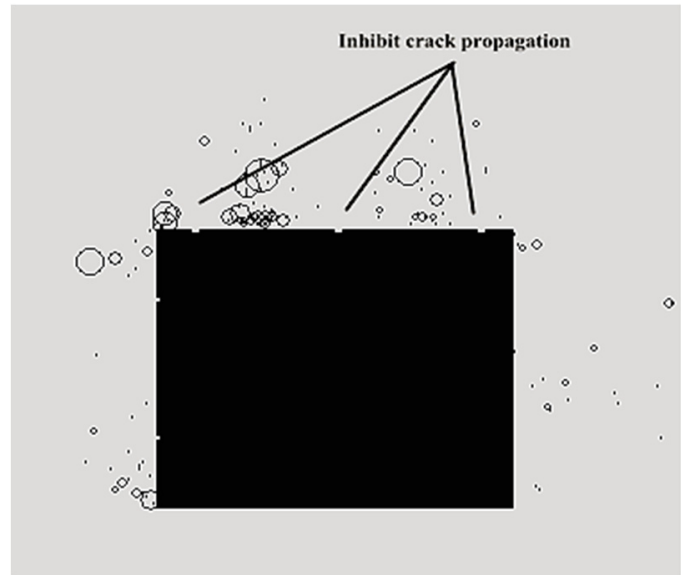

Fig. 11. Surrounding rock dynamic disturbance with supporting roadway

\section{Conclusions}

1) For roadway surrounding rock with obvious dynamic disturbance, the compressive stress wave generates a tensile stress reflected wave on the roadway wall, the compressive stress value can eliminate the above-mentioned tensile stress wave influence, in the roadway support, it is necessary to provide a certain compressive stress to the surrounding rock of the surrounding roadway wall.

2) Anchoring the surrounding rock can significantly inhibited the expansion and dislocation slip of tensile cracks and shear cracks on both sides of the roadway, it has a good inhibitory effect on the tensile and compressive failure of carbonaceous mudstone in the roof and it also has a good inhibitory effect on the shear failure of the top carbonaceous mudstone.

3) Because the dynamic load damage to the carbonaceous mudstone between the roof anchors is obvious, the anchor spacing and row spacing should be reduced or enhance the stiffness and main power of the protective surface member.

\section{References}

[1] Lu C. P., Liu G. J., Wang H. Y., et al. Numerical investigation of rock burst effect of shock wave on underground roadway. Shock and Vibration, Vol. 2015, 2015, p. 867582.

[2] Dong Q., Li X., Zhao H. Study on damage characteristic of underground cavern blasting excavation based on dynamic damage constitutive model. Proceedings of the International Conference on Advances in Energy, Environment and Chemical Engineering, 2015.

[3] Weng L., Li X., Tao M. Influence of geostress orientation on fracture response of deep underground cavity subjected to dynamic loading. Shock and Vibration, Vol. 2015, 2015, p. 575879.

[4] Li S. C., Wang Q., Wang H. T., et al. Model test study on surrounding rock deformation and failure mechanisms of deep roadways with thick top coal. Tunneling and Underground Space Technology, Vol. 47, 2015, p. 52-63. 
[5] Li X., Weng L. Numerical investigation on fracturing behaviors of deep-buried opening under dynamic disturbance. Tunneling and Underground Space Technology, Vol. 54, 2016, p. 61-72.

[6] Li X., Gong F., Tao M., et al. Failure mechanism and coupled static-dynamic loading theory in deep hard rock mining: a review. Journal of Rock Mechanics and Geotechnical Engineering, Vol. 9, Issue 4, 2017, p. 767-782.

[7] Du K., Tao M., Li X., et al. Experimental study of slabbing and rock burst induced by true-triaxial unloading and local dynamic disturbance. Rock Mechanics and Rock Engineering, Vol. 49, Issue 9, 2016, p. 3437-3453.

[8] Cao P., Liu T., Pu C., et al. Crack propagation and coalescence of brittle rock-like specimens with pre-existing cracks in compression. Engineering Geology, Vol. 187, 2015, p. 113-121.

[9] Cao R., Cao P., Lin H., et al. Mechanical behavior of brittle rock-like specimens with pre-existing fissures under uniaxial loading: experimental studies and particle mechanics approach. Rock Mechanics and Rock Engineering, Vol. 49, Issue 3, 2016, p. 763-783.

[10] Zhao Y., Zhang L., Wang W., et al. Cracking and stress-strain behavior of rock-like material containing two flaws under uniaxial compression. Rock Mechanics and Rock Engineering, Vol. 49, Issue 7, 2016, p. 2665-2687.

[11] Weng L., Huang L., Taheri A., et al. Rock burst characteristics and numerical simulation based on a strain energy density index: A case study of a roadway in Linglong Gold Mine, China. Tunneling and Underground Space Technology, Vol. 69, 2017, p. 223-232.

[12] Gong W., Peng Y., He M., et al. Thermal image and spectral characterization of roadway failure process in geologically 45 inclined rocks. Tunneling and Underground Space Technology, Vol. 49, 2015, p. 156-173.

[13] Xiao C., Zheng H., Hou X., et al. A stability study of goaf based on mechanical properties degradation of rock caused by rheological and disturbing loads. International Journal of Mining Science and Technology, Vol. 25, Issue 5, 2015, p. 741-747.

[14] Zhao Y., Zhang L., Wang W., et al. Transient pulse test and morphological analysis of single rock fractures. International Journal of Rock Mechanics and Mining Sciences, Vol. 91, 2017, p. 139-154.

[15] Zhao Y., Tang J., Chen Y., et al. Hydromechanical coupling tests for mechanical and permeability characteristics of fractured limestone in complete stress-strain process. Environmental Earth Sciences, Vol. 76, Issue 1, 2017, p. 24.

[16] Zhao Y., Luo S., Wang Y., et al. Numerical analysis of karst water inrush and a criterion for establishing the width of water-resistant rock pillars. Mine Water and the Environment, Vol. 36, Issue 4, 2017, p. 508-519.

[17] Meng Q., Han L., Chen Y., et al. Influence of dynamic pressure on deep underground soft rock roadway support and its application. International Journal of Mining Science and Technology, Vol. 26, Issue 5, 2016, p. 903-912.

[18] Yu W., Liu F. Stability of close chambers surrounding rock in deep and comprehensive control technology. Advances in Civil Engineering, Vol. 2018, 2018, p. 6275941.

[19] Jia P., Zhu W. C. Mechanism of zonal disintegration around deep underground excavations under triaxial stress-Insight from numerical test. Tunneling and Underground Space Technology, Vol. 48, 2015, p. 1-10.

[20] Cheng Y., Bai J., Ma Y., et al. Control mechanism of rock burst in the floor of roadway driven along next goaf in thick coal seam with large obliquity angle in deep well. Shock and Vibration, Vol. 2015, 2015, p. 750807.

[21] Meng Q., Han L., Xiao Y., et al. Numerical simulation study of the failure evolution process and failure mode of surrounding rock in deep soft rock roadways. International Journal of Mining Science and Technology, Vol. 26, Issue 2, 2016, p. 209-221.

[22] Yang S. Q., Chen M., Jing H. W., et al. A case study on large deformation failure mechanism of deep soft rock roadway in Xin'An coal mine, China. Engineering Geology, Vol. 217, 2017, p. 89-101.

[23] Chen Y., Lu A., Mao X., et al. Nonlinear dynamics mechanism of rock burst induced by the instability of the layer-crack plate structure in the coal wall in deep coal mining. Shock and Vibration, Vol. 2017, 2017, p. 4051967.

[24] Zhao Y., Wang Y., Wang W., et al. Modeling of non-linear rheological behavior of hard rock using triaxial rheological experiment. International Journal of Rock Mechanics and Mining Sciences, Vol. 93, 2017, p. 66-75.

[25] Zhao Y., Zhang L., Wang W., et al. Separation of elastoviscoplastic strains of rock and a nonlinear creep model. International Journal of Geomechanics, Vol. 18, Issue 1, 2017, p. 04017129. 
[26] Zhao Y., Zhang L., Wang W., et al. Creep behavior of intact and cracked limestone under multi-level loading and unloading cycles. Rock Mechanics and Rock Engineering, Vol. 50, Issue 6, 2017, p. $1409-1424$.

[27] Wang H., Jiang Y., Xue S., et al. Assessment of excavation damaged zone around roadways under dynamic pressure induced by an active mining process. International Journal of Rock Mechanics and Mining Sciences, Vol. 77, 2015, p. 265-277.

[28] Wang W. L., Jing H. W., Yang D. L. Failure mechanism analysis and countermeasures of high-level stress soft rock roadway. Coal Mine Safety, Vol. 41, Issue 9, 2010, p. 129-132.

[29] Zhang Z. Q., Li Y. Study on stress evolution laws and control of surrounding rock of deep soft roadway under different lateral pressure coefficients. Chinese Coal, Vol. 44, Issue 3, 2018, p. 63-69.

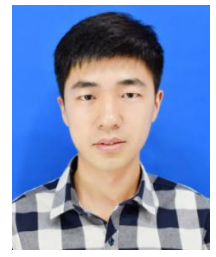

Hongfei Gu is currently the Master student in School of Resource, Environment and Safety Engineering, Hunan University of Science and Technology. His current research interests include rock mechanics and rock formation control.

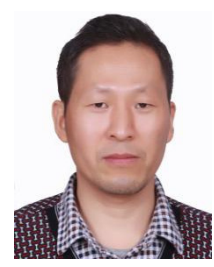

Qingfeng Li received the Ph.D. degree in engineering mechanics from Mining University of China, Xuzhou, China, in 2007. He is currently the Professor of Hunan University of Science and Technology. He has been devoted to the study of rock mechanics and rock formation control.

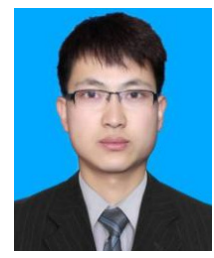

Yuejin Peng is currently the graduate student in Hunan University of Science and Technology. He is engaged in the study of rock mechanics.

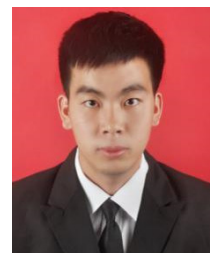

Qiyun Huang is currently the Master student in Hunan University of Science and Technology, mainly engaged in the study of rock mechanics.

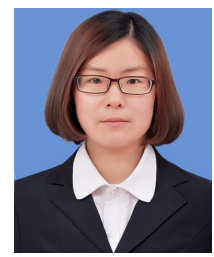

Jianan Yang is currently the Master student in Hunan University of Science and Technology, mainly engaged in the study of rock mechanics. 